\section{Fractured needle during endoscopic ultrasound- guided fine-needle aspiration of a pancreatic head} mass

Endoscopic ultrasound (EUS)-guided fineneedle aspiration (FNA) is a safe procedure with a low complication rate [1]. To the best of our knowledge, there has only been one previous report of inadvertent fracturing of an FNA needle, which occurred during an attempted EUS-guided rendezvous for an inaccessible main pancreatic duct [2]. We present the case of a 75-year-old woman with an unresectable pancreatic head mass, who was referred to us for EUS-FNA after biliary stent placement.

The procedure was performed by an experienced endosonographer from the duodenal bulb using a 22-gauge needle. The needle was inserted into the periphery of the mass to avoid passing through the plastic stent, and the fanning technique was used. At the end of the first pass, an unusual hyperreflecting line was observed, corresponding to the needle tract ( $\bullet$ Fig. 1), which suggested that the needle may have broken during the sampling procedure. This was confirmed when the needle was advanced outside the external sheath to collect the specimen. The extremity of the broken needle was further identified protruding from the mucosa of the upper duodenal bulb (ه Fig. 2).

After various attempts at retrieval, the needle was grasped from the terminal end using a snare and was removed completely, without any consequences to the patient. The needle segment measured 4 $\mathrm{cm}(\bullet$ Fig. 3, $\bullet$ Video 1$)$. There was no obvious cause of this incident. However, it is possible that the plastic stent could have been a relevant factor in the breaking of the needle.

This case highlights the importance of ensuring that the correct EUS-FNA procedure is followed. After confirmation of a needle fracture, endoscopic removal can be accomplished with caution using the proper endoscopic accessories, in order to avoid potential damage to both the patient and the echoendoscope.

Endoscopy_UCTN_Code_CPL_1AL_2AF

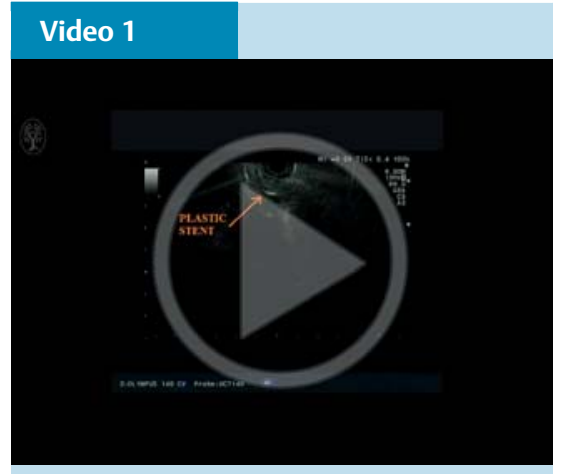

Fractured needle during endoscopic ultrasound-guided fine-needle aspiration of a pancreatic head mass.

Competing interests: A. Larghi is a consultant for Cook Medical and Boston Scientific.

\section{Mihai Rimbaș ${ }^{1,2}$, Fabia Attili' ${ }^{1}$ Santiago Andrade Zurita ${ }^{1}$, Shyam Dang ${ }^{1,3}$, Alberto Larghi ${ }^{1}$}

${ }^{1}$ Digestive Endoscopy Unit, Catholic University, Rome, Italy

${ }^{2}$ Colentina Clinical Hospital, Bucharest, Romania

${ }^{3}$ Division of Gastroenterology and Hepatology, University of Arkansas Medical Sciences, Little Rock, Arkansas, United States

\section{References}

1 Dumonceau JM, Polkowski M, Larghi A et al. Indications, results, and clinical impact of endoscopic ultrasound (EUS)-guided sampling in gastroenterology: European Society of Gastrointestinal Endoscopy (ESGE) clinical guideline. Endoscopy 2011; 43: $897-$ 912

2 DeWitt J, Sherman S, Lillemoe KD. Fracture of an EUS-guided FNA needle during an attempted rendezvous for an inaccessible pancreatic duct. Gastrointest Endosc 2011; 73: $171-173$

\section{Bibliography}

Dol http://dx.doi.org/

10.1055/s-0034-1392661

Endoscopy 2015; 47: E432

(c) Georg Thieme Verlag KG

Stuttgart · New York

ISSN 0013-726X

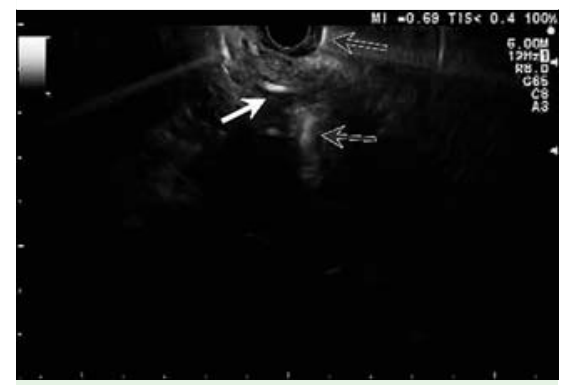

Fig. 1 Endoscopic ultrasound image of the fractured needle within the pancreatic head mass, which could be followed up to the duodenal wall (gray arrows) and was located beside the previously placed plastic stent (white arrow).

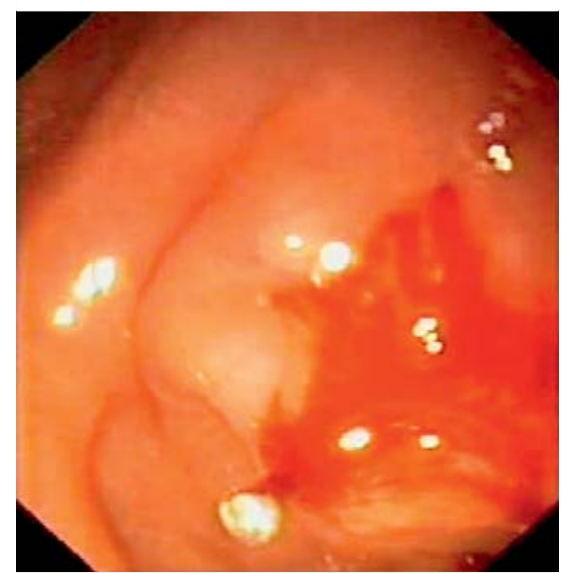

Fig.2 Endoscopic image of the extremity of the needle fragment protruding from the duodenal bulb.

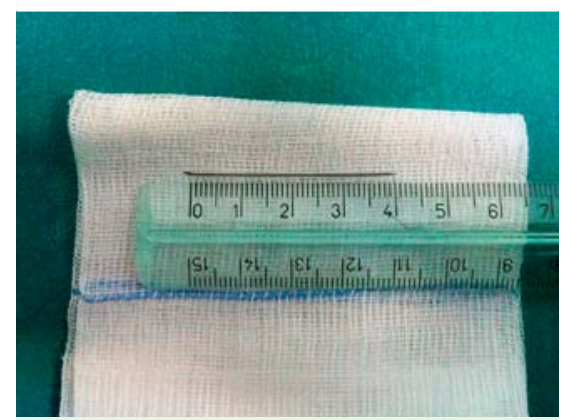

Fig.3 Image of the removed fractured needle fragment, which measured $4 \mathrm{~cm}$ in length.

Corresponding author Alberto Larghi, MD, PhD Digestive Endoscopy Unit Catholic University Largo A. Gemelli 8 00168, Rome

Italy

Fax: +39-06-30156581

alberto.larghi@yahoo.it 